\section{Catamenial pneumothorax: Some commentaries}

\section{To the Editor:}

We read with interest the article by Korom and associates ${ }^{1}$ reporting 3 new cases of catamenial pneumothorax and with an excellent review of the literature. The reports outline the frequent lack of recognition of diaphragmatic endometriosis as the causative factor of catamenial pneumothorax, even in patients submitted to surgical exploration with videoassisted thoracoscopy. In a previous prospective study on catamenial pneumothorax, ${ }^{2}$ we pointed out that exploration of the whole thoracic cavity should be mandatory in these patients. We suggested that patients should be positioned in the posterolateral decubitus position to correctly explore the whole hemidiaphragm, which is often incompletely visualized if the patient is positioned as for a lateral thoracotomy.

We would like to comment on 2 points concerning the article by Korom and associates. ${ }^{1}$ First, they state that not all of a patient's menses coincide with a pneumothorax, but each episode of a catamenial pneumothorax is associated with the menstrual flow. Definition of catamenial pneumothorax implies a strict temporal relationship with menses, and the condition has been often defined as a recurrent pneumothorax occurring within 72 hours from the onset of menstruation. ${ }^{2}$ However, the recurrent character in relation with the immediate premenstrual period has also been reported. ${ }^{3,4}$ It has been recently shown that a recurrent endometriosis-related pneumothorax might be observed also in the intermenstrual period. ${ }^{5}$ Therefore it has been suggested that thoracic endometriosis should be suspected in any case of recurrent pneumothorax in women of reproductive age, even when episodes occur out of the menstrual period. ${ }^{5}$

Second, Korom and associates ${ }^{1}$ proposed plication of the portion of diaphragm involved by endometriosis rather than excision and repair. Furthermore, in their opinion hormonal therapy should be considered as a secondary therapeutic option to be used in case of failure of surgical intervention: they adopted this strategy in one of the 3 patients. We do not agree with these suggestions. In our opinion resection of all the visible lesions (when technically feasible) should be carried out not only to optimally treat the cause of pneumothorax but also to avoid further intrathoracic spread of the disease. ${ }^{2}$ In the absence of a hormonal treatment, endometrial implants (which are left in place by simple plication) would continue to undergo cyclical changes, with possible consequences in terms of partial diaphragmatic disruption and formation of new holes. We think that patients should be offered the best chance of cure when the disease is first diagnosed. For this reason, we proposed surgical excision of the diseased structures, pleurodesis, and a short course of hormonal treatment. ${ }^{2}$ Pleural symphysis takes some weeks to be effective after surgical intervention, and if menstruation occurs before pleurodesis is achieved, a recurrence of pneumothorax will be likely.

Marco Alifano, $M D$

Pierre Magdeleinat, MD

Jean François Regnard, MD

Unité de Chirurgie Thoracique

Hotel-Dieu Hospital

1, Place du Parvis Notre-Dame

Paris 75004, France

\section{References}

1. Korom S, Canyurt H, Missbach A, Schneiter D, Kurrer MO, Haller U, et al. Catamenial pneumothorax revisited: clinical approach and systematic review of the literature. J Thorac Cardiovasc Surg. 2004;128:502-8.

2. Alifano M, Roth Th, Camilleri-Broet S, Schussler O, Magdeleinat P, Regnard JF. Catamenial pneumothorax: a prospective study. Chest. 2003;124:1004-8.

3. Bagan P, Le Pimpec Barthes F, Assouad J, Soulimas R, Riquet M. Catamenial pneumothorax: retrospective study of surgical treatment. Ann Thorac Surg. 2003;75:378-81.

4. Yamazaki S, Ogawa J, Koide S, Shohzu A, Osamura Y. Catamenial pneumothorax associated with endometriosis of the diaphragm. Chest. 1980;77:107-9.

5. Alifano M, Cancellieri A, Fornelli A, Trisolini R, Boaron M. Endometriosis-related pneumothorax: clinico-pathologic observations from a newly diagnosed case. $J$ Thorac Cardiovasc Surg. 2004;127:1219-21.

doi:10.1016/j.jtcvs.2004.11.025

\section{Reply to the Editor:}

My colleagues and I thank Dr Alifano for his interest in our work and would like to respond to the comments brought forward concerning our recently published review on catamenial pneumothorax (CPT). ${ }^{1}$ First, they debate the classic description of CPT. As a time-honored working definition, this phenomenon has been described on the basis of its temporal relationship with the menstrual cycle. In the majority of published cases, CPT has been reported to reach clinical significance (culminating in the diagnosis of spontaneous pneumothorax) within 72 hours of the beginning of the menstrual flow. Yet as Dr Alifano has pointed out, there are some reports on CPT being diagnosed beyond this strict timeframe. ${ }^{2}$ Because we believed the same, we have refrained from quoting this arbitrary 72-hour definition but rather stated that each episode of CPT is associated with the menstrual flow. Being aware of the pathophysiologic background, it is obvious that the individual relevance of a developing pneumothorax might be subject to a wider chronologic margin.

Second, Dr Alifano criticizes our therapeutic approach in CPT. He suggests "excision of all visible lesions (when technically feasible)." Similarly, we stated the following: "All accessible lesions should be excised, and plication is recommended to seal and strengthen this area." In contrast to our approach, Dr Alifano adds a 6-month course of hormonal therapy to his surgical therapy in all cases. Describing this therapeutic regimen in a recent publication, Alifano and associates ${ }^{3}$ cite only one (early) recurrence out of 8 treated patients; however, in this study the mean follow-up time is 6.6 months, with a range from 2 to 15 months. In contrast, on the basis of our experience and the world literature, abrogating the ovarian steroid genesis in mature women with CPT constitutes a significant alteration of the hormonal equilibrium in these patients. Without data on the long-term follow-up with these courses, we believe that abrogating the ovarian steroid genesis in a young woman is not a justifiable first-line approach for this clinical picture because excision and plication of the diaphragm might prevent recurrence of pneumothorax, as reported in several cases.

Walter Weder, MD Division of Thoracic Surgery University Hospital of Zurich Ramistrasse 100 Zurich CH-8091, Switzerland

\section{References}

1. Korom S, Canyurt H, Missbach A, Schneiter D, Kurrer MO, Haller U, et al. Catamenial pneumothorax revisited: clinical approach and systematic review of the literature. J Thorac Cardiovasc Surg. 2004;128:502-8.

2. Alifano M, Cancellieri A, Fornelli A, Trisolini R, Boaron M. Endometriosis-related pneumothorax: clinicopathological observations from a newly diagnosed case. $J$ Thorac Cardiovasc Surg. 2004;127:1219-21.

3. Alifano M, Roth Th, Camilleri-Broet $\mathrm{S}$, Schussler O, Magdeleinat P, Regnard J-F. 